Original Research Paper

\title{
Tumor Suppressor p53 Gene Mutations Pattern Induced by Repeated Fried Palm Oil in Rats
}

\author{
${ }^{1}$ Abeer A.I. Hassanin, ${ }^{2}$ Abeer G.A. Hassan, ${ }^{3}$ Saadia, A.Ali and ${ }^{4}$ Takao Itakura \\ ${ }^{1}$ Department of Animal Wealth Development, Faculty of Veterinary Medicine, Suez Canal University, Ismailia, Egypt \\ ${ }^{2}$ Department of Biochemistry, Faculty of Veterinary Medicine, Suez Canal University, Ismailia, Egypt \\ ${ }^{2}$ Department of Chemistry, Al Jouf University, Al-Jawf, Saudi Arabia \\ ${ }^{3}$ Department of Physiology, Faculty of Veterinary Medicine, Suez Canal University, Ismailia, Egypt \\ ${ }^{4}$ Laboratory of Marine Biotechnology, Faculty of Fisheries, Kagoshima University, 4-50-20 Shimoarata, \\ Kagoshima 890-0056, Japan
}

Article history

Received: 24-07-2014

Revised: 08-09-2014

Accepted: 10-12-2014

Corresponding Author: Abeer A.I. Hassanin Department of Animal Wealth Development, Faculty of Veterinary Medicine, Suez Canal University, Ismailia, Egypt

Email: drabeer2000@gmail.com

\begin{abstract}
The present study aimed to examine the presence of p53 gene mutations in white albino rats fed on repeated fried palm oil. Eighteen sexually mature male Albino rats were used throughout the experiment. Rats were divided randomly into three groups, 6 animals each, namely; control group (CO) which orally administered by distilled water (NO) group which fed on basal diet containing fresh pure palm oil (FO) group which fed on the basal diet containing repeated fried palm oil with a dose of $150 \mathrm{~mL} \mathrm{~kg}^{-1}$ diet. At the end of the experiment, liver samples were taken, kept at $-80^{\circ} \mathrm{C}$ for genetic alteration studies. Results shows the presence of fifty eight base-pair substitutions mutations which include a total of twelve base pair substitutions arose at A:T base pairs, fourteen base pair substitutions arose at G:C base pairs, Eighteen base pair substitutions at $\mathrm{T}$ : A base pairs, fourteen base pair substitutions arose at $\mathrm{C}: \mathrm{G}$ base pairs. Of the fifty eight substitutional mutations recorded, there were thirty one silent (same sense) mutations and twenty seven missense mutations which causing the substitution of amino acids.
\end{abstract}

Keywords: Mutation Spectra, p53 Gene, Commercial Palm Oil, Albino Rat

\section{Introduction}

In today's society with all its modern trappings, repeated frying with vegetable oils is a widely used procedure for food preparation (Bouchon, 2009; Shila et al., 2011). Several studies reported that using vegetable oils in prolonged frying processes may be a principle or strong reason for inducing or forming mutagenic or carcinogenic diets (Hamilton et al., 1997; Coultate, 2009; Gouveia De Souza et al., 2004; Paiva-Martins and Gordon, 2005; Khalil et al., 2009).

During the frying process at temperatures of $170^{\circ}$ $200^{\circ} \mathrm{C}$, steam formed from moisture in the food being fried help volatile products rise to the surface of the frying medium and into the kitchen atmosphere, imparting a mixture of fried-flavours and off-flavours. The non-volatile compounds formed, however, gradually build up in the oil as it is being repeatedly-used for food frying operations. These non-volatiles, primarily "Polar Compounds" (PC) and to a lesser extent lipid polymers, get absorbed into fried foods and eventually end up in our body system (Wai, 2007). The nutritional consequences of ingesting deep-fried oils include a variety of symptoms ranging from allergic reactions of digestive tract, growth retardation, increase in liver and kidney weights, to other biochemical reactions.

A series of Heterocyclic Aromatic Amines (HAAs) that have been found to be mutagens/carcinogens may arise in oil of fat during prolonged frying processes (Nagao et al., 1997; Raloff, 1999). The mutagenic and possibly carcinogenic products of HAAs are metabolized and activated by enzymes of cytochrome systems-mediated $\mathrm{N}$ hydroxylation to a number of hydroxylated metabolites which react with the DNA to induce mutations (Davis and Snyderwine, 1995; Schut et al., 1997).

Tumor suppressor genes are normal genes that slow down cell division, repair DNA mistakes, or tell cells when to die (a process known as apoptosis or programmed cell death). When tumor suppressor genes don't work properly, cells can grow out of control, which can lead to cancer. Many different tumor suppressor 
genes have been found, including TP53 (p53), BRCA1, BRCA2, APC and RB1 (ACS, 2011).

The p53 tumor suppressor gene is the most apparent among these because mutations have been demonstrated in a fraction of almost every tumor type tested. Most mutation detected was a single nucleotide mismatch Single Nucleotide Polymorphism (SNP) that occurred in the p53-gene coding region. P53 mutations indicate that the sites and features of DNA base changes differ among the various tumor types and depend on carcinogen type. Thus; the molecular epidemiology of p53 mutations allows the possibility of correlating particular mutations with specific carcinogens and establishing one step in the causal pathway between exposure to carcinogens and the development of cancer. Moreover, these carcinogens leave molecular fingerprints on the p53 gene (Nadia and Marwa, 2012).

The tumor suppressor gene p53 is mutated in about $40 \%$ of human cancer cases (Greenblatt et al., 1994). In addition, p53 mutations have been detected, albeit at lower frequencies, in numerous chemically induced (Ruggeri et al., 1993; Barbin et al., 1997) and sporadic tumors in rodents (Rivkina et al., 1994), cat (Mayr et al., 1995), dog (Devilee et al., 1994) and cattle (Dequiedt et al., 1995). Most of them are missense mutations clustered in the DNA binding domain of the protein (Greenblatt et al., 1994) that alter its tumor suppressor function (Cho et al., 1994).

Assessing p53 status may very well be beneficial in early detection and monitoring of tumor relapse, by detecting mutant p53 DNA. Furthermore, analysis of p53 status can serve as a tool in the prediction of effective therapeutic regimens, whereas p53 itself, particularly mutant p53, may represent targets for cancer therapy (Rivlin et al., 2011).

Therefore, the present study focused on monitoring p53 gene mutations pattern in liver of mature male albino rats fed on basal diet containing thermally oxidized commercial palm oil repeatedly used for frying process (FO) in a dose of $150 \mathrm{~mL} \mathrm{~kg}^{-1}$ diet for one month.

\section{Material and Method}

\section{Material}

Unpackaged palm oil was used in this experiment because it is less expensive and more available to consumers, especially in rural areas in Egypt. The oil and potatoes were obtained from local market in Ismailia governorate, Egypt.

\section{Animals}

Eighteen sexually mature male Albino rats (weighing approximately $150 \pm 10 \mathrm{~g}$ ) were obtained from Faculty of
Veterinary Medicine animal house and used throughout the experiment. Rats were housed in metal cages, fed on a standard diet and water ad libitum, maintained under a $12 \mathrm{~h}$ light/dark cycle, at a laboratory temperature of $23 \pm 3^{\circ} \mathrm{C}$. Rats were acclimatized for two weeks before starting the experiments. All rats were handled in accordance with the standard guide for the care and use of laboratory animals. Killing was performed under sodium pentobarbital anesthesia and all efforts were made to minimize suffering.

\section{Preparation of Frying Oil}

For 2 liter palm oil, pan frying was performed in an uncovered stainless steel pan fryer, where about $400 \mathrm{~g}$ potatoes or tamea (Reciprocal) were divided into 2 batches and fried each time at $175 \pm 5^{\circ} \mathrm{C}$. The frying processes were repeated for 15 times (12.3 $\mathrm{min}$ each) twice daily for 8 successive days. No replenishment of oil was considered and oil was taken out at the end of the experiment, filtered and placed in a bottle in the refrigerator $\left(4^{\circ} \mathrm{C}\right)$, then thoroughly mixed with the basal diet.

\section{Experimental Design}

The animals were divided randomly into three groups, 6 animals each, namely: Group 1, animals were orally administered by distilled water and considered as Control (CO). Group 2, was fed basal diet containing fresh pure palm oil (NO) that was not used in frying process. Group 3, was fed the basal diet containing thermally oxidized palm oil repeatedly used for frying process (FO) with a dose of $150 \mathrm{~mL} \mathrm{~kg}^{-1}$ diet (Ahmed and Sharma, 1997). All rat groups were fed the corresponding previously mentioned diets for one month.

At the end of the experiment, all animals were fasted for $12 \mathrm{~h}$ then killed under sodium pentobarbital anesthesia. Liver tissue samples were taken, snap frozen in liquid nitrogen at $-196^{\circ} \mathrm{C}$, kept at $-80^{\circ} \mathrm{C}$ for genetic alteration studies.

\section{Total RNA Extraction}

Total RNA was extracted from liver samples using Quick Gene RNA tissue kit S II (RT-S2) (Life Sciences Advanced Technologies Inc.) according to the manufacture's protocol. Total RNA concentration and purity were determined spectrophotometrically as described by Sambrook and Russel (2001) and A260/A280 ratio was between 1.7 and 1.9.

\section{Reverse Transcriptase-Assisted Polymerase Chain Reaction}

Reverse transcription of total RNA was performed with Superscript II reverse transcriptase (Gibco BRL, USA) to generate 3' -RACE-Ready first strand cDNA using a SMART TM RACE cDNA amplification kit (Clontech, USA) according to the manufacture's protocol. 
Table 1. Oligonucleotide primers used in PCR amplification of p53 gene

\begin{tabular}{lllllll}
\hline $\begin{array}{l}\text { Primer } \\
\text { name }\end{array}$ & $\begin{array}{l}\text { Reference } \\
\text { gene for location }\end{array}$ & $\begin{array}{l}\text { Location } \\
(\mathrm{np})\end{array}$ & $\begin{array}{l}\text { Length } \\
(\mathrm{mer})\end{array}$ & $\begin{array}{l}\text { Primer } \\
\text { sequence }\end{array}$ & Tm( $\left({ }^{\circ} \mathrm{C}\right)$ & $\mathrm{GC}\left(\mathbf{( \%}^{\circ}\right)$ \\
\hline 1F & NM_030989 & $441-464$ & 24 & 5'- AAC TAT GGC TTC CAC CTG GGC TTC -3' & 67.6 & 54.2 \\
$1 \mathrm{R}$ & NM_030989 & $1216-1239$ & 24 & 5'- TGG TCT TCG GGT AGC TGG AGT GAG -3' & 68.0 & 58.3 \\
\hline
\end{tabular}

Oligonucleotide Primers and PCR Amplification of p53 Gene

Two degenerate primers, one sense (F) and one antisense (R) were designed by web-based software Primer3Plus (Untergasser et al., 2007) from the published DNA sequence of Rattus norvegicus tumor protein p53 (Tp53), mRNA (accession no. NM_030989.3). The primers sequences are shown in Table 1.

\section{PCR and Agarose Gel Electrophoresis}

PCR reactions contained $3^{\prime}$-RACE-Ready cDNA $(2.5 \mu \mathrm{L}), 20 \mu \mathrm{M}$ each of degenerate primers, $25 \mu \mathrm{L}$ of SapphireAmp Fast PCR Master Mix (Takara, Japan) in a final volume of $50 \mu \mathrm{L}$. The cycling conditions were as follows: 35 cycles of denaturation at $94^{\circ} \mathrm{C}$ for $30 \mathrm{sec}$, annealing at $68^{\circ} \mathrm{C}$ for $30 \mathrm{sec}$ and extension at $72^{\circ} \mathrm{C}$ for 3 min. PCR products were analyzed on $1 \%$ agarose gels. The DNA band of expected size was excised with a scalpel, purified using GFX PCR DNA and a gel band purification kit (GE Health Care, UK), the PCR products obtained were cloned into PT7BlueT- vector (Novagen, USA). Purified plasmids were directly sequenced by dye terminator cycle sequencing using an ABI PRISM dye terminator cycle sequencing kit (PE Biosystemes, USA) and an applied Biosystems 3130 $\times$ L DNA sequencer.

\section{Phylogenetic Analysis}

The resulted nucleotide sequences were aligned with the corresponding functional p53 sequences available in GenBank. DNA sequences with the following Genbank accession numbers were retrieved from the database and used in the phylogenetic analysis: NM 030989.3 (Rat p53), AB020317 (Mouse p53), AF30785̄1 (Human p53), sequence alignment was performed by the CLUSTAL W method using Laser gene Megalign program (Ver $5.52,2003$, DNASTAR Inc).

\section{Results}

\section{Partial Nucleotide Sequence Analysis of P53 cDNA}

A nucleotide sequence of $799 \mathrm{bp}$ of the Open Reading Frame (ORF) of p53 cDNA was amplified using the sense and antisense primers in Control (CO), Normal Oil (NO) and Fired Oil (FO) groups respectively (Fig. 1-3). The amplified region corresponding to the p53 cDNA gene codon regions 104-370 (exons 4-9). Phylogenetic analysis (Fig. 4) clearly shows that the resulted sequences are closely related to functional rat p53, Rattus norvegicus, tumor protein p53 (Tp53) sequence.
Table 2. Percent identities of p53 cDNA sequences

\begin{tabular}{llllll}
\hline & L.NO & L.FO & Rat & Mouse & Human \\
\hline L.C & 100 & 91.6 & 100 & 91.7 & 85.4 \\
L.NO & & 91.6 & 100 & 91.7 & 85.4 \\
L.FO & & & 91.6 & 99.9 & 83.5 \\
Rat & & & & 85.5 & 68.8 \\
Mouse & & & & & 74.9 \\
\hline
\end{tabular}

Table 2 showing the percent identities of the resulted sequences with the sequence of p53 cDNA in other species. P53 cDNA sequence from the control group and group fed on normal oil shows the highest identity $(100 \%)$ with rat $\mathrm{p} 53$, followed by $91.7 \%$ with mouse $\mathrm{p} 53$ then ended by $85.4 \%$ with human $\mathrm{p} 53$. The percent identity between p53 cDNA sequence in control group and group fed on repeated fried oil was $91.6 \%$.

\section{Detection of p53 Sequence Mutations}

Sequence alignment of control, Normal oil and fried oil groups p53 sequences by the CLUSTAL W method using Laser gene Megalign program (Ver 5.52,2003, DNASTAR Inc) (Fig. 5) shows presence of fifty eight base-pair substitutions mutations. A total of twelve base pair substitutions arose at A:T base pairs (five $\mathrm{A}: \mathrm{T} \rightarrow \mathrm{T}: \mathrm{A}$, five $\mathrm{A}: \mathrm{T} \rightarrow \mathrm{G}: \mathrm{C}$ and two $\mathrm{A}: \mathrm{T} \rightarrow \mathrm{C}: \mathrm{G})$. However, there were a total of fourteen base pair substitutions arose at $\mathrm{G}: \mathrm{C}$ base pairs (three $\mathrm{G}: \mathrm{C} \rightarrow \mathrm{T}: \mathrm{A}$, eight $\mathrm{G}: \mathrm{C} \rightarrow \mathrm{A}: \mathrm{T}$ and three $\mathrm{G}: \mathrm{C} \rightarrow \mathrm{C}: \mathrm{G})$. At $\mathrm{T}:$ A base pairs, there were a total of eighteen base pair substitutions include (fourteen $\mathrm{T}: \mathrm{A} \rightarrow \mathrm{C}: \mathrm{G}$ and four $\mathrm{T}: \mathrm{A} \rightarrow \mathrm{G}: \mathrm{C}$ ). Finally, A total of fourteen base pair substitutions arose at $C: G$ base pairs (eight $C: G \rightarrow T: A$, four $C: G \rightarrow G: C$ and two $C: G \rightarrow A: T)$. Of the fifity eight substitutional mutations recorded, there were thirty one silent (same sense) mutations and twenty seven missense mutations which causing the substitution of amino acids (Fig. 6).

\section{Discussion}

As social economic and cultural conditions have changed over the twentieth century, significant alteration occurred in eating habits, including eating outside home and especially in fast food restaurants, which lead to increased consumption of oils used in deep fat frying (Weisburger, 2002).

Carcinogenesis is a complex process characterized by the cumulative activation of various oncogenes and the inactivation of suppressor genes. 
Abeer A.I. Hassanin et al. / American Journal of Animal and Veterinary Sciences 2014, 9 (4): 230.338 DOI: 10.3844/ajavssp.2014.230.338

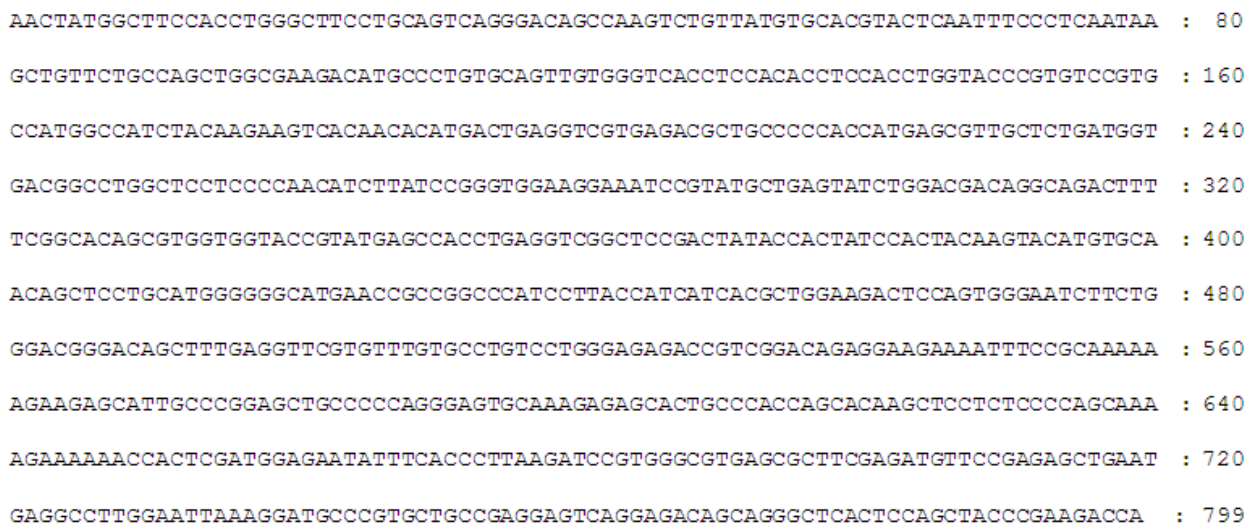

Fig. 1. Partial Nucleotide sequence (799 bp) of the Open Reading Frame (ORF) of P53 cDNA in Control (CO) group

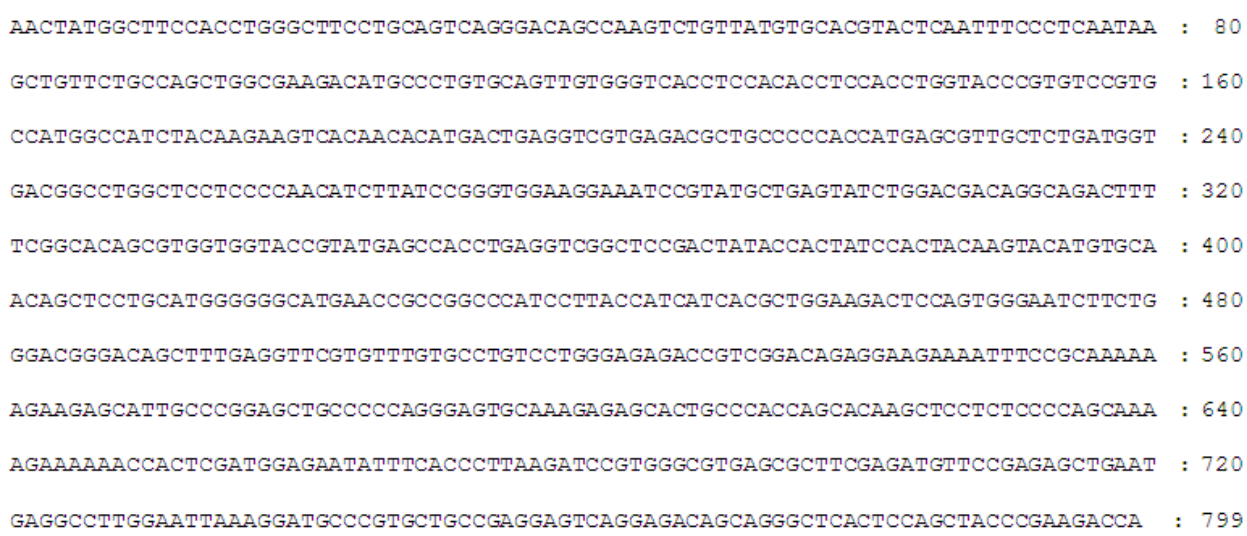

Fig. 2. Partial Nucleotide sequence (799 bp) of the Open Reading Frame (ORF) of p53 cDNA in Normal oil (NO) group

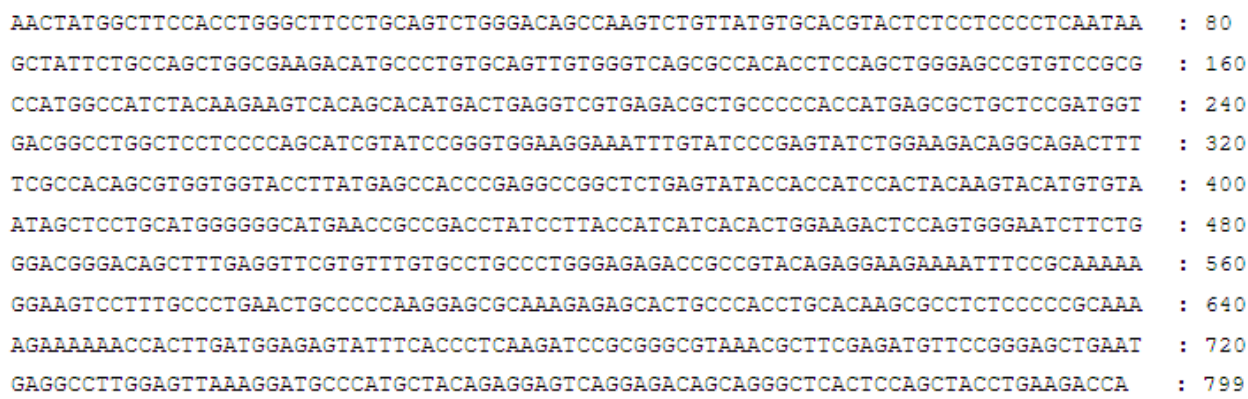

Fig. 3. Partial Nucleotide sequence (799 bp) of the Open Reading Frame (ORF) of p53 cDNA in Fried oil (FO) group

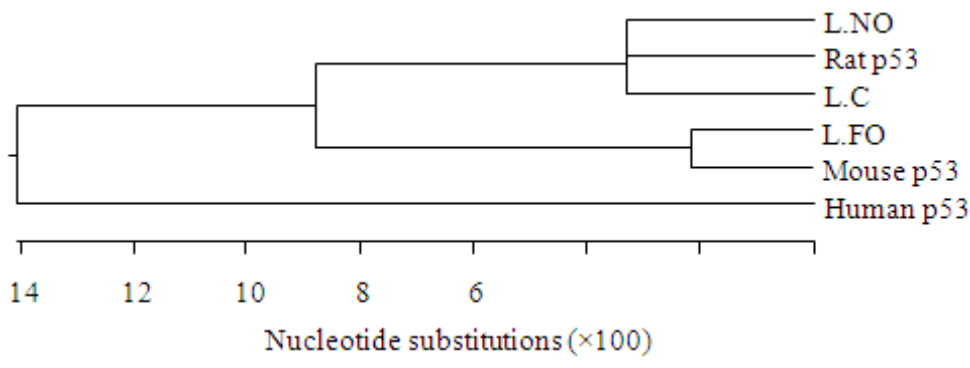

Fig. 4. Phylogenetic tree of the obtained rat p 53 sequences with other species functional p $53 \mathrm{cDNAs}$ 


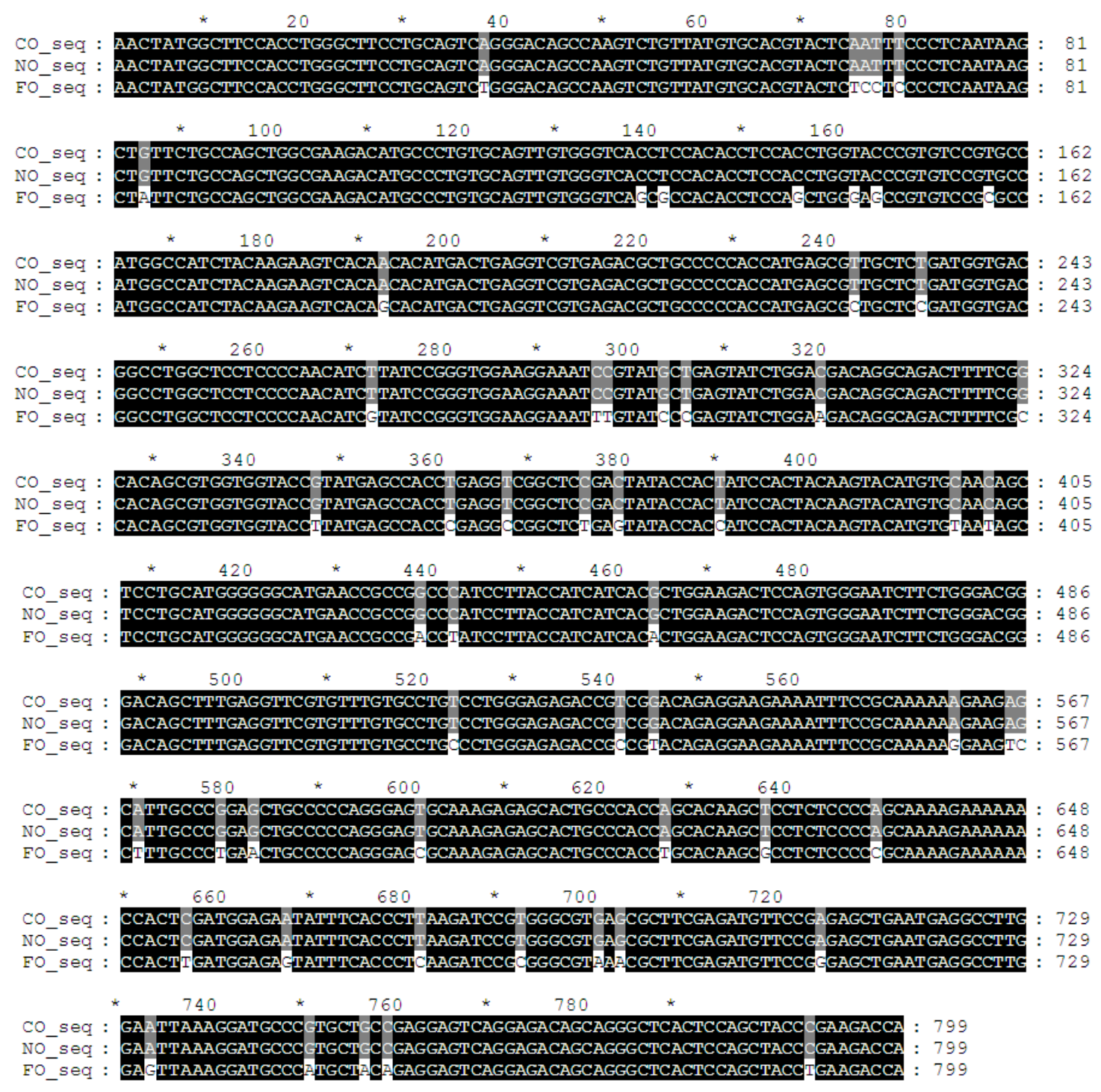

Fig. 5. Sequence alignment of Control (CO), Normal Oil (NO) and Fried Oil (FO) groups p53 partial sequences by the CLUSTAL W method using Laser gene Megalign program (Ver 5.52,2003, DNASTAR Inc.) showing the mutation spectra (Single nucleotide polymorphism) in p53 gene sequence, where identical bases highlighted in black and polymorphic variations highlighted in gray

About $30-40 \%$ of human hepatocarcinomas and $20-60 \%$ of rat experimental tumors demonstrated mutations of p53 gene (Vancutsem et al., 1994; Masui et al., 1997; De Miglio et al., 2001). Interestingly, the spectrum of p53 mutations can provide clues to the etiology and molecular pathogenesis of neoplasia. The frequency and type of mutation can also be considered as a molecular dosimeter of carcinogen exposure and thus can provide information for cancer risk assessment.

Chemically induced rat liver cancer proceeds through multiple, distinct initiation-promotion-progression stages and mutation of the suppressor p53 gene has been found in relatively early pre-neoplastic lesions in the rat liver. Therefore, mutant p53 molecules have been thought to have some unique properties that are important in carcinogenesis in rats (Haas and Pitot, 1998).

In this study, the analyses of p53 gene mutations induced by repeated fried oil in rat liver were confined to exons 4-9, which include the highly conserved domains of the gene and are the sites at which mutations in human and experimental liver tumors have been most frequently detected (Hollstein et al., 1991; Smith et al., 1993; Vancutsem et al., 1994). The findings of this study show that p53 mutations are a frequent event in the liver of rats fed on repeated fried oil. Our results are in an agreement with that of Mariam et al. (2010) which indicated that fried oil food has a mutagenic effect on the genomic materials of male mice. 


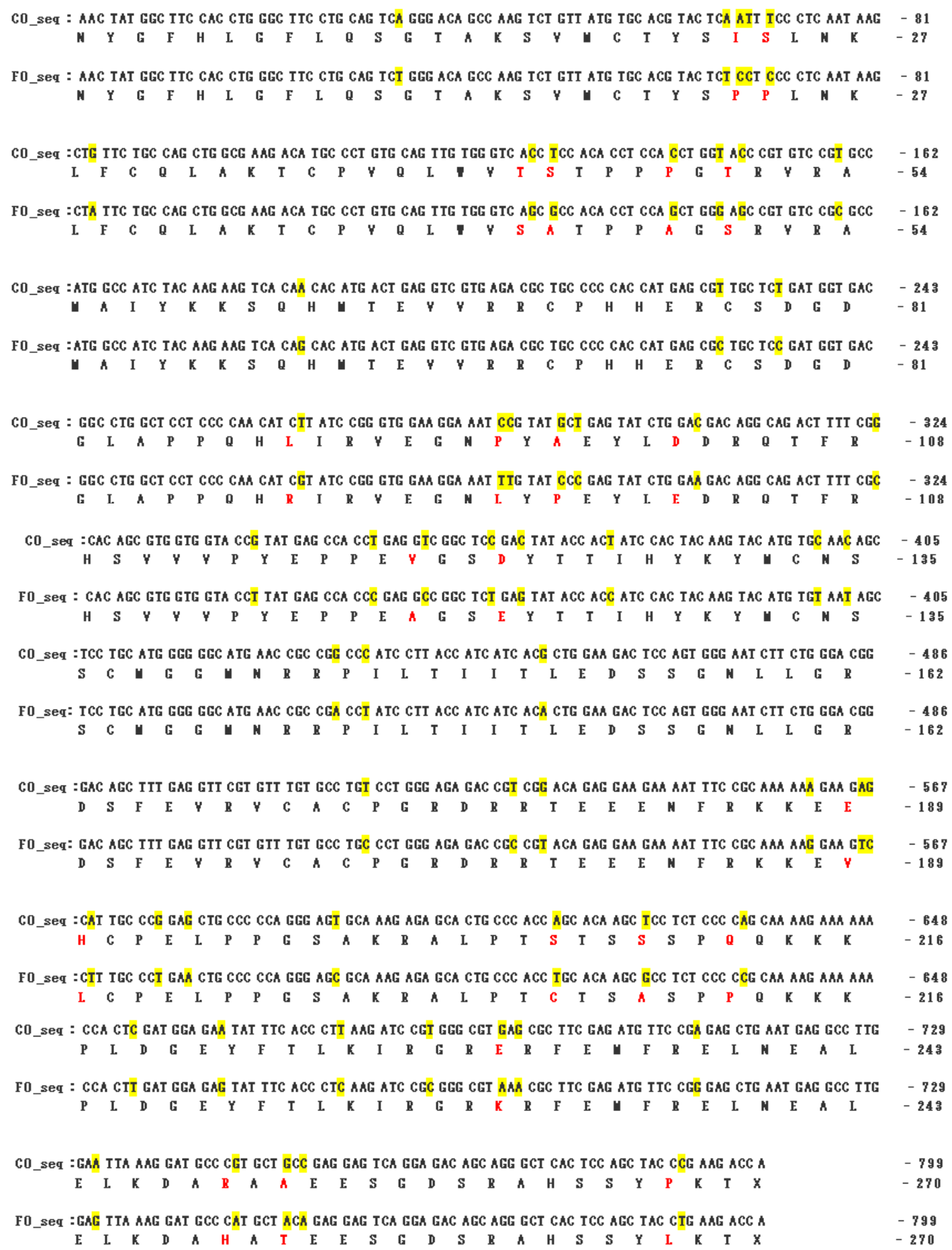

Fig. 6. Substitutional mutations in p53 gene product

This mutagenic effect may be due to the formation of oxidative compounds of lipidperoxid or Heterocyclic Aromatic Amines (HAAs), that have been found to be mutagenic or carcinogenic (Hamilton et al., 1997; Starvic et al., 1997; Raloff, 1999; Coultate, 2009; Bou et al., 2008). Lipidperoxid compounds may be associated with generation of free radicals causing DNA fragmentation or DNA mutation (Lampe, 1999; Coultate, 2009; Nicolle et al., 2003; Bou et al., 2008).

The second major finding of this study is that the majority of mutations were missense mutations 12 of which arose at A:T base pairs, 14 at G:C, 18 at T:A and 
14 of which were $\mathrm{C}: \mathrm{G}$ base pairs transversions (Fig. 5). These data in rats clearly indicate a specific mutation spectrum in liver associated with repeated fried oil. The vast majority of cancer-associated mutations inTP53 are missense mutations. The great majority of these missense mutations are clustered within the central most conserved region of p53 that spans the DNA-binding domain and among these area small number (approximately six) of "hot spot"' residues that occur with unusually high frequency (Harris and Hollstein, 1993; Cho et al., 1994; Petitjean et al., 2007).

In most cases, the p53 gene is mutated; giving rise to a stable mutant protein whose accumulation is regarded as a hallmark of cancer cells. Mutant p53 proteins not only lose their tumor suppressive activities but often gain additional oncogenic functions that endow cells with growth and survival advantages. Interestingly, mutations in the p53 gene were shown to occur at different phases of the multistep process of malignant transformation, thus contributing differentially to tumor initiation, promotion, aggressiveness and metastasis (Rivlin et al., 2011).

\section{Conclusion}

In conclusion, Assessing p53 status may very well be beneficial in early detection and monitoring of tumor relapse, by detecting mutant p53 DNA. Furthermore, analysis of p53 status can serve as a tool in the prediction of effective therapeutic regimens, whereas p53 itself, particularly mutant p53, may represent targets for cancer therapy (Rivlin et al., 2011).

\section{Funding Information}

This research received no grant from any funding agency in the public, commercial or not-for-profit sectors.

\section{Author's Contributions}

Abeer A.I. Hassanin: Designed the research plan and organized the study, have made a substantial contribution to the concept and design, acquisition of data or analysis and interpretation of data, approved the version to be published.

Abeer G.A. Hassan: Designed the research plan and organized the study have made a substantial contribution to the concept and design, acquisition of data or analysis and interpretation of data, coordinated the mouse work.

Saadia, A. Ali: Have made a substantial contribution to the concept and design, acquisition of data or analysis and interpretation of data.

Takao Itakura: Drafted the article or revised it critically for important intellectual content.

\section{Ethics}

All rats were handled in accordance with the standard guide for the care and use of laboratory animals. Killing was performed under sodium pentobarbital anesthesia and all efforts were made to minimize suffering.

\section{References}

ACS, 2011. American Cancer Society, Inc.

Ahmed, R.S. and S.B. Sharma, 1997. Biochemical studies on combined effects of garlic (Allium sativum Linn) and ginger (Zingiber officinale Roscoe) in albino rats. Ind. J. Experim. Biol., 35: 841-843.

Barbin, A., O. Froment and S. Boivin, 1997. p53 gene mutation in rat liver tumors induced by vinyl chloride. Cancer Res., 57: 1695-1698.

Bou, R., R. Codonyb, A. Tresb, E.A. Deckera and F. Guardiolab, 2008. Determination of hydroperoxides in foods and biological samples by the ferrous oxidation-xylenol orange method: A review of the factors that influence the method's performance. Analytical Biochemistry, 377: 1-15.

DOI: $10.1016 /$ j.ab.2008.02.029

Bouchon, P., 2009. Understanding Oil Absorption during Deep-Fat Frying. In: Advances in Food and Nutrition Research, S. Taylor (Ed.), Elsevier Press, pp: 209-234.

Cho, Y., S. Gorina, P.D. Jeffrey and N.P. Pavletich, 1994. Crystal structure of a p53 tumor suppressor-DNA complex: Understanding tumorigenic mutations. Science, 265: 346-355.

DOI: $10.1126 /$ science. 8023157

Coultate, T.P., 2009. Food: The Chemistry of its Components. 5th Edn., Royal Society of Chemistry, Cambridge, ISBN-10: 0854041117, pp: 501.

Davis, C.D. and E.G. Snyderwine, 1995. Protective effect of $\mathrm{N}$-acetylcysteine against heterocyclic amine-induced cardiotoxicity in cultured myocytes and in rats. Fd. Chem. Toxic., 33: 641-651.

DOI: 10.1016/0278-6915(95)00033-X

De Miglio, M.R., M.R. Muroni, M.M. Simile, P. Virdis and G. Asara et al., 2001. Frequent loss of heterozygosity at the Hcrl (hepatocarcinogenesis resistance) locus on chromosome 10 in primary hepatocellular carcinomas from LFF1 rat strain. Hepatology, 33: 1110-1117.

DOI: 10.1053/jhep.2001.23795

Dequiedt, F., R. Kettmann, A. Burny and L. Willems, 1995. Mutations in the p53 tumor-suppressor gene are frequently associated with bovine leukemia virus-induced leukemogenesis in cattle but not in sheep. Virology, 209: 676-683.

DOI: $10.1006 /$ viro.1995.1303 
Devilee, P., I.S. Van Leeuwen, A. Voesten, G.R. Rutteman and C.J. Cornelisse, 1994. The caninep53gene is subject to somatic mutations in thyrold carcinoma. Anticancer Res., 14: 2039-2046.

Gouveia De Souza, A., J.C. Oliveira Santos, M.M. Conceicao, M.C. Dantas Silva and S. Prasad, 2004. A thermoanalytic and kinetic study of sunflower oil. Braz. J. Chem. Eng., 21: 265-273. DOI: $10.1590 /$ S0104-66322004000200017

Greenblatt, M.S., W.P. Bennett, M. Hollstein and C.C. Harris, 1994. Mutations in the p53 tumor suppressor gene: Clues to cancer etiology and molecular Pathogenesis. Cancer Res., 54: 4855-4878.

Haas, M.J. and H.C. Pitot, 1998. Characterization of rare p53 mutants from carcinogen-treated albuminsimian virus 40 T-antigen transgenic rats. Mol. Carcinog., 21: 128-134. DOI: 10.1002/(SICI)10982744(199802)21:2<128::AID-MC7>3.0.CO;2-J

Hamilton, R.J., C. Kalu, E. Prisk, F.B. Padley and H. Pierce, 1997. Chemistry of free radicals in lipids. Food Chemistry, 60: 193-199.

DOI: $10.1016 / \mathrm{S} 0308-8146(96) 00351-2$

Harris, C.C. and M. Hollstein, 1993. Clinical implications of the p53 tumor-suppressor gene. N. Engl. J. Med., 329: 1318-1327.

DOI: 10.1056/NEJM199310283291807

Hollstein, M., D. Sidransky, B. Vogelstein and C.C. Harris, 1991. p53 mutations in human cancers. Science, 253: 49-53. DOI: 10.1126/science. 1905840

Khalil, W.K.B., H.A.M. Abd, M.G. Eshak, I.M. Farag and K.Z. Ghanem, 2009. Biological studies on the protective role of artich oke and green pepper against potential toxic effect of thermally oxidized oil in mice. Arab J. Biotech., 12: 27-40.

Lampe, J.W., 1999. Health effects of vegetables and fruit: Assessing mechanisms of action in human experimental studies. Am. J. Clin. Nutr., 70: 475S-490S.

Mariam, G.E., S.G. Inas, K.B.K. Wagdy, M.F. Ibrahim and Z.G. Kadry, 2010. Genetic alterations induced by toxic effect of thermally oxidized oil and protective role of tomatoes and carrots in mice. J. Am. Sci., 6: 175-188.

Masui, T., H. Nakanishi, K. Inada, T. Imai and Y. Mizoguchi et al., 1997. Highly metastatic hepatocellular carcinomas induced in male F344 rats treated with $\mathrm{N}$-nitrosomorpholine in combination with other hepatocarcinogens show a high incidence of p53 gene mutations along with altered mRNA expression of tumor-related genes. Cancer Lett, 112: 33-45. DOI: 10.1016/S0304-3835(96)04543-0

Mayr, B., G. Schaffner, R. Kurzbauer, A. Schneider and M. Reifinger et al., 1995. Mutations in tumor suppressor gene in two feline fibrosarcomas. Br. Vet. J., 151: 707-713.

DOI: $10.1016 / \mathrm{S} 0007-1935(95) 80151-0$
Nadia, H.R.A. and Y. Marwa, 2012. p53 mutations as fingerprints of environmental carcinogens. IJRRAS, 11: 310-321.

Nagao, M., T. Ushumia, M. Toyota, R. Inoue and T. Sugimura, 1997. Genetic changes induced by heterocyclic amines. Mutat. Res., 376: 161-167. DOI: 10.1016/S0027-5107(97)00039-0

Nicolle, C., N. Cardinault, O. Aprikian, J. Busserolles and P. Grolier et al., 2003. Effect of carrot intake on cholesterol metabolism and on antioxidant status in cholesterol-fed rat. Eur. J. Nutr., 42: 254-261. DOI: $10.1007 / \mathrm{s} 00394-003-0419-1$

Paiva-Martins, F. and M.H. Gordon, 2005. Interactions of ferric ions with olive oil phenolic compounds. J. Agric. Food Chemistry, 53: 2704-2709. DOI: $10.1021 / \mathrm{jf0} 481094$

Petitjean, A., M.I.W. Achatz, A.L. Borresen-Dale, P. Hainaut and M. Olivier, 2007. TP53 mutations in human cancers: Functional selection and impact on cancer prognosis and outcomes. Oncogene, 26: 2157-2165. DOI: $10.1038 /$ sj.onc. 1210302

Raloff, J., 1999. New recipes for making serfously browned meats less of a cancer risk. Weekly Newsmagazine Sci., 155: 17-24.

Rivkina, M.B., Cullin, J.M., Robinson, W.S. and Marion, P.L., 1994. State of the p53gene in hepatocellular carcinomas of ground squirrels and woodchucks with past and ongoing infection with heapdnaviruses. Cancer Res., 54: 5430-5437.

Rivlin, N., R. Brosh, M. Oren and V. Rotter, 2011. Mutations in the p53 tumor suppressor gene: Important milestones at the various steps of tumorigenesis. Genes Cancer, 2: 466-474. DOI: $10.1177 / 1947601911408889$

Ruggeri, B., M. DiRado, S.Y. Zhang, B. Bauer and T. Goodrow et al., 1993. Benzo[a]pyrene-induced murine skin tumors exhibit frequent and characteristic $G$ to $T$ mutations in the p53 gene. Proc. Natl. Acad. Sci., USA 90: 1013-1017.

DOI: 10.1073 pnas.90.3.1013

Sambrook, J. and D.V. Russel, 2001. Molecular Cloning: A Laboratory Manual, 1st Edn., Cold Spring Harbor, New York, ISBN-10: 0879695773, pp: 2344.

Schut, H.A.J., C.L. Wang, L.M. Twining and K.M. Earle, 1997. Formation and persistence of DNA adducts of 2-amino-3-methylimidazo[4,5-f]quinoline (IQ) in $\mathrm{CDF}_{1}$ mice fed a high $\omega-3$ fatty acid diet. Mutat. Res., 378: 23-30. DOI: 10.1016/S0027-5107(97)00094-8

Shila, S., J. Jalal, A.O. Ali, A. Leila and R. Roghayeh et al., 2011. The effect of consuming oxidized oil supplemented with fiber on lipid profiles in rat model. J. Res. Med. Sci., 16: 1541-1549. 
Smith, M.L., L. Yeleswarapu, P. Scalamogna, J. Locker and B. Lombardi, 1993. p53 mutations in hepatocellular carcinomas induced by a cholinedevoid diet in male Fischer 344 rats. Carcintogentesis, 14: 503-510.

DOI: $10.1093 /$ carcin/14.3.503

Starvic, B., B.P.Y. Lau, T.I. Matula, R. Klassen and D. Lewis et al., 1997. Mutagenic Heterocyclic Aromatic Amines (HAAs) in 'processed food flavour' samples. Food Chemical Toxicology, 35: 185-197. DOI: 10.1016/S0278-6915(96)00119-6

Untergasser, A., H. Nijveen, X. Rao, T. Bisseling and R. Geurts et al., 2007. Primer3Plus, an enhanced web interface to Primer3. Nucl. Acids Res., 35: W71-W74. DOI: $10.1093 /$ nar/gkm306
Vancutsem, P.M., Lazarus, P., Williams, G.M. 1994. Frequent and specific mutations of the rat p53 gene in hepatocarcinomas induced by tamoxifen. Cancer Res., 54: 3864-3867.

Wai, T.N.K., 2007. Local Repeatedly-Used Deep Frying Oils Are Generally Safe. Int. e-Journal Sci. Med. Educ., 1: 55-60.

Weisburger, J.H., 2002. Lifestyle, health and disease prevention: The underlying mechanisms. Eur. J. Cancer Prevention, 11: 1-7. 